\title{
Development of gluten free breads from Colocasia esculenta flour blended with
}

\section{hydrocolloids and enzymes}

Jehannara Calle ${ }^{1,2}$, Yaiza Benavent-Gil ${ }^{2}$, Cristina M. Rosell ${ }^{2 *}$

${ }^{1}$ Food Research Institute for the Food Industry (IIIA), Carretera al Guatao km $3^{1 / 2}$, La Lisa 17100, La Habana, Cuba.

${ }^{2}$ Institute of Agrochemistry and Food Technology (IATA-CSIC), C/ Agustin Escardino, 7, Paterna 46980, Valencia, Spain.

*Corresponding author e-mail: crosell@iata.csic.es. Phone number +34 963900022. Fax number: +34963636301

\begin{abstract}
Colocasia esculenta, belonging to the Araceae family, represents an attractive alternative as gluten-free (GF) main ingredient owing its healthy pattern. The aim was to explore the GF breadmaking potential of Colocasia spp. cormels flour, thermally treated or blended with hydrocolloids (HPMC, xanthan gum, guar gum), enzymes (glucose oxidase or proteases) or potato starch. A total of eight formulations were used to obtain GF bread-like products. Resulting breads were characterized based on their technological quality, but also on their functional quality by in vitro starch digestion. Colocasia spp. cormels flour-based breads displayed similar quality parameters observed in previous reported GF formulations. The addition of an endoprotease allowed developing breads with higher specific volume, but the alcalase type protease increased crumb softness. In general, resulting GF breads contained higher SDS and RS fraction than RDS fractions. A better starch digestibility pattern than those previously reported in GF breads was also observed, which confirm the potential of Colocasia spp. cormels flour as novel nutritive source of GF flours.
\end{abstract}

Keyword: bread; Colocasia esculenta; digestibility; gluten-free; glycemic index 


\section{Introduction}

2 Over the last decades, the popular belief that gluten free (GF) diet is a healthier option

3 along with gluten-related disorders are driving an increasing number of consumers to

4 opt for a GF diet as a lifestyle choice. Consequently, numerous researches have been

5 conducted on GF products to improve their technological and nutritional properties

6 (Capriles \& Arêas, 2014; Capriles, dos Santos, \& Arêas, 2016). Nevertheless, diverse

7 studies stated that consumers remain unsatisfied with the quality of GF products (do

8 Nascimento, Fiates, dos Anjos, \& Teixeira, 2014), while others highlighted their lack of

9 nutritional values compared to their gluten-containing counterparts (Pellegrini \&

10 Agostoni, 2015). Therefore, a balance between technological properties and nutritional

11 value is necessary to match the consumer's requests.

12 Currently, refined flours or starches are the main ingredients used to produce

13 commercial GF products, specifically GF breads. As a result, breads have poor

14 technological quality including dry crumbling crumb, poor mouthfeel and poor flavor

15 (Gallagher, Gormley, \& Arendt, 2003). These GF breads also show deficient nutritional

16 values including low protein content and higher carbohydrate than the recommended

17 intake (Segura \& Rosell, 2011). The inclusion of alternative GF flours into GF breads

18 recipes is one of the main approaches to improve their claimed poor technological and

19 nutritional quality (Alvarez-Jubete, Arendt, \& Gallagher, 2010). Alternative flours from

20 pseudocereals, roots, tubers and legumes sources have been applied successfully to

21 improve the nutrient profiles of the GF products (Capriles et al., 2014). Nevertheless,

22 their minimal structure-building potential requires the use of additives or ingredients.

23 Thus far, hydrocolloids, proteins, enzymes have been mixed with blends of GF flours

24 and starches to improve the technological quality of end-products (Masure, Fierens, \&

25 Delcour, 2016). Apart from mentioned inferior technological properties, the inclusion of 
all these alternative flours into GF breads is limited owing its detrimental effect on the sensory properties of end-products (Capriles et al., 2016). Therefore, further searches on other nutritive GF flours are needed.

The Colocasia esculenta (L.) Schott (Colocasia spp.) rhizome is grown largely in Cuba

30 for their edible corms and cormels (Calle, Benavent-Gil, Garzón, \& Rosell, 2019). Its

31 nutritional components make this material very attractive to improve the nutritional value of foods (Kaushal, Kumar, \& Sharma, 2015). The Colocasia spp. has been stated as a good source of protein (11 - 16\%), crude fiber (5 - 9\%) and potassium (2271$4276.06 \mathrm{mg} / 100 \mathrm{~g}$ ), but also other minerals including iron, calcium, sodium, magnesium, phosphorus, zinc and copper (Arıcı, Yıldırım, Özülkü, Yaşar, \& Toker, 2016).

Furthermore, the Colocasia spp. flour also contains vitamins and has antioxidant activity (Chandrasekara \& Josheph Kumar, 2016).

Despite the evidence of positive nutritional value of Colocasia spp. flour and its promising economic value, as far as authors knowledge, there are no studies about the utilization of this flour in GF breadmaking. Ammar, Hegazy, and Bedeir (2009) incorporated 5,10,15 and 20\% Colocasia spp. flour into a wheat flour-based dough and concluded that the adding of $10 \%$ Colocasia spp. flour results in bread with similar rheological and organoleptic properties than those observed in wheat flour bread (Emmanuel, Osuchukwu, \& Oshiele, 2010). Sanful (2011) also replaced wheat flour with different percentages of Colocasia spp. flour, increasing the amounts of ash, total carbohydrates and fiber as increasing the taro flour level in the breads.

47 The main objective of the present study was to explore the GF breadmaking potential of Colocasia spp. flour. Furthermore, based on the aforementioned complex GF systems found in the literature, the effect of different additives including hydrocolloids, enzymes and starch was also evaluated to overcome the technological challenge involved in the 
51 gluten removal. The suitability of Colocasia spp. flour individually, thermally

52 pretreated or blended with different additives for application in a GF systems was investigated and their effects on the technological and nutritional properties of the GF bread products were evaluated.

\section{Materials and methods}

\subsection{Materials}

57 Cormels from freshly Colocasia spp. MC-2012, harvested at 9 months of maturity, were collected from National Institute of Tropical Food Research Farms in Cuba. The rhizomes were cleaned to remove all foreign matter, peeled and cut into slices of $1 \mathrm{~cm}$.

60 After mixing with water and a solution of sodium metabisulfite $(20 \mathrm{mg} / \mathrm{kg})$ during 30

61 min to avoid oxidation reaction, the slices were dehydrated with a forced convection

62 tray dryer (Keller, Ihne \& Tesch KG No. 3709, Lampertheim, Germany) at $45^{\circ} \mathrm{C}$ during

$6324 \mathrm{~h}$. Then, the dry slices were milled and the obtained flour kept at $4^{\circ} \mathrm{C}$ for subsequent analyses. Hydroxypropylmethylcellulose (HPMC, Methocel $\left.{ }^{\mathrm{TM}} \mathrm{K} 4 \mathrm{M}\right)$ was generously donated by Dow Pharma \& Food Solutions (La Plaine Saint Denis, France). Guar gum 663500 and xanthan gum food grade were obtained from EPSA (Valencia, Spain) and 67 Jungbunzlauer (Wulzeshofen, Austria), respectively. Gluzyme Mono 10000 BG (EC 68 1.1.3.4) containing 10,000 glucose oxidase U/g, iZyme BA (EC 3.4.21.1) containing 0.15 AU/g endo-protease activity, and Alcalase 1.5 MG Type FG (EC 3.4.21.62) containing 1.5 AU/g alcalase activity (Subtilisin type) were provided by Novozymes (Bagsværd, Denmark). Potato starch was purchased from Tereos Syral (Marckolsheim,

72 France). All other ingredients were acquired in the local market. All reagents were of analytical grade and used without further purification. 
75 Standard methods were used to determine the flour characteristics (AACC, 1999;

76 AOAC, 1990). Moisture was measured by oven drying at $130^{\circ} \mathrm{C}$ for $90 \mathrm{~min}$ (AACCI

77 Method 44-15.02). Total nitrogen content was analyzed according to the Kjeldahl

78 method (AACCI methods 46-12.01) using a nitrogen-to-protein conversion factor of

79 6.25. Fat content was quantified following the Soxhlet method (AACC Method 30-

80 25.01). Ash content was determined by incinerating samples in a muffle at $900^{\circ} \mathrm{C}$ for 2

81 h (AACC Method 08-01.01). The crude fiber content of the samples was analyzed in

82 accordance with the AOAC Method 973.18. Carbohydrate content was estimated by

83 difference.

84 Water binding capacity (WBC) was analyzed according to the method described by

85 Cornejo and Rosell (2015). Results were expressed as grams of water retained per gram 86 of solid.

\subsection{Baking process}

A total of eight reported GF bread formulations were selected (Calle, Villavicencio,

89 Rosell, \& Bernabé-Marques, 2014; Gujral \& Rosell, 2004; Marco \& Rosell, 2008;

90 Morreale, Garzón, \& Rosell, 2018; Renzetti \& Arendt, 2009a) and adapted to Colocasia

91 spp. cormels flour characteristics. All of them were prepared relying on a simple GF

92 formulation based on Colocasia spp. cormels flour, present individually, pretreated or

93 blended with different ingredients (starches, enzymes and other hydrocolloids) widely

94 used in the design of GF bread. To obtain pretreated Colocasia spp. cormels flour, $50 \mathrm{~g}$

95 of resulting Colocasia spp. cormels flour were mixed during $5 \mathrm{~min}$ with $113.5 \mathrm{~mL}$ of

96 boiled water, which corresponded to the water binding capacity required for hydrating

$9750 \mathrm{~g}$ of flour. This partially pregelatinized flour was directly used in the recipe and it

98 was referred as pretreated flour. The formulations used are summarized in Table 1,

99 which were based on flour as follows: $100 \%$ of rhizome flour (F1); $50 \%$ of flour 
100 blended with $50 \%$ of pregelatinized flour (F2); $100 \%$ of flour blended with

101 hydrocolloids (F3 and F4); 100\% of flour blended with enzymes (F5, F6 and F7); and

$10280 \%$ of flour blended with $20 \%$ of potato starch (F8).

103 GF doughs were prepared by mixing the dry ingredients and then by adding the oil and

104 water with the compressed yeast previously dissolved at $20^{\circ} \mathrm{C}$. Mixing was carried out

105 in a Robot Coupe RM8 (Barcelona, Spain) at speed 3 for 8 min. 50 g-Dough pieces

106 were put into pans and placed into a proofer (Lezo, Spain) for $50 \mathrm{~min}$ at $30^{\circ} \mathrm{C}$ and a

107 relative humidity of $85 \%$. The breads were baked in an electric oven (F106, FM

108 Industrial, Córdoba, Spain) at $185^{\circ} \mathrm{C}, 80 \%$ of humidity for $20 \mathrm{~min}$. After baking, bread

109 loaves were removed from the pans and cooled at room temperature for $45 \mathrm{~min}$. Loaves

110 packed in polyethylene bags to prevent drying were stored at $24^{\circ} \mathrm{C}$ for $24 \mathrm{~h}$ and then

111 used for further analysis. Baking was performed on 2 independent trials and 5 loaves

112 were prepared for each bread type at each baking trial.

\section{$113 \quad$ 2.4.Quality assessment of the GF breads}

114 Resulting GF breads were evaluated in terms of quality parameters as previously

115 described by Matos and Rosell (2013). Bread moisture content was determined in two

116 steps following the AACC (1999). Bread volume was measured by the rapeseed

117 displacement method. Specific volume $\left(\mathrm{cm}^{3} / \mathrm{g}\right)$ was calculated as the ratio between the

118 volume of the bread and its weight. Weight loss during baking was assessed by

119 weighing the pans before and after baking. These measurements were carried out in

120 three breads of each batch.

121 The texture parameters including hardness $(\mathrm{g})$, cohesiveness, chewiness $(\mathrm{g})$ resilience

122 and springiness were evaluated using a Texture Analyzer TA-XT2i (Stable Micro

123 Systems, Surrey, UK) equipped with a $5 \mathrm{Kg}$ load cell, which compresses the bread

124 crumb with a $25 \mathrm{~mm}$ aluminum cylindrical probe. Bread samples were sliced into 10 
$125 \mathrm{~mm}$ slices and analyzed with a texture profile analysis (TPA) double compression test.

126 During the test, samples were compressed twice up to 50\% strain (penetration of its

127 original height) at a cross head speed of $1 \mathrm{~mm} / \mathrm{s}$ and $30 \mathrm{~s}$ gap between compressions

128 with a trigger force of $5 \mathrm{~g}$. Data was acquired using Texture expert software and showed

129 as the average value taking three breads from each batch.

130 Crumb color was recorded using a Minolta colorimeter (Chromameter CR-400/410

131 Konica Minolta. Japan) after standardization with a white calibration plate $\left(L^{*}=96: 9\right.$;

$\left.132 a^{*}=-0.04 ; b^{*}=1.84\right)$. The data collected from three slices of each bread measured at

133 three different locations of the slices were averaged and expressed using CIE- $L * a * b *$

134 scale where $L^{*}$ indicates lightness, $a^{*}$ indicates hue on a green $(-)$ to red $(+)$ axis, and $b^{*}$

135 indicates hue on a blue (-) to yellow (+) axis.

$136 \quad$ 2.5.In vitro digestion

137 Digestibility of GF breads was assayed following the method described by (Benavent-

138 Gil \& Rosell, 2017b). The amount of starch fractions based on the hydrolysis rate of

139 starch was calculated and expressed in amount of glucose released $(\mathrm{mg} / 100 \mathrm{mg})$ by

140 using the method of Englyst, Veenstra, and Hudson (1996). Rapidly digestible starch

141 (RDS) was defined as the starch fraction that was hydrolyzed within 20 min of

142 incubation, slowly digestible starch (SDS) was the starch fraction hydrolyzed within 20

143 and $120 \mathrm{~min}$, and resistant starch (RS) was defined as the starch fraction that remaining

144 unhydrolyzed after $16 \mathrm{~h}$ of incubation.

145 Glucose measure was determined in supernatant samples using a glucose oxidase-

146 peroxidase (GOPOD) kit (Megazyme, Dublin, Ireland). Starch was calculated as

147 glucose $(\mathrm{mg}) \times 0.9$.

148 Experimental data were fitted to first order equation to study the kinetics of in vitro

149 digestion (Goñi, García-Alonso, \& Saura-Calixto, 1997): $C=C_{\infty}\left(1-\mathrm{e}^{-k t}\right) . C$ was the 
150 concentration at $t$ time, $C_{\infty}$ was the equilibrium concentration or maximum hydrolysis

151 extent, $k$ was the kinetic constant and $t$ was the time chosen. The hydrolysis index (HI)

152 was calculated as the ratio area under the hydrolysis curve $(0-180 \mathrm{~min})$ of the sample

153 and area of a standard material (white bread) over the same period of time. The

154 expected glycemic index $(e G I)$ was obtained using the equation $e G I=8.198+0.862 \mathrm{HI}$

155 (Granfeldt, Björck, Drews, \& Tovar, 1992).

$156 \quad$ 2.6.Statistical analysis

157 The data reported in the tables and figures are average values of duplicates and

158 expressed as a mean \pm standard deviation. Data was subjected to analysis of variance

159 (ANOVA) to separate the effect of different additives. Fisher's least significant test was

160 used for assessment of significant differences among experimental mean values with a

161 significance level of 0.05 . Pearson correlation coefficient $(r)$ and $p$-value were used to

162 indicate correlations and their significance using Statgraphics Centurion XVII software

163 (Bitstream, Cambridge, N).

\section{3. Results and discussion}

3.1.Proximate composition of raw Colocasia esculenta cormels flour

166 The composition of the Colocasia spp. flour used in the present study expressed in

167 percentage (based on dry basis) was as follows: moisture: $6.33 \pm 0.02 \%$, protein: $8.28 \pm$

$1680.07 \%$, ash: $5.04 \pm 0.00 \%$, fat: $0.53 \pm 0.00 \%$, crude fiber: $4.38 \pm 0.23 \%$ and

169 carbohydrates: $75.44 \pm 0.35$. Data obtained are in agreement with literature (Temesgen

170 \& Retta, 2015a). As expected, Colocasia spp. cormels flour displayed high

171 carbohydrate content, but it also proved to be a good source of minerals and fiber. The

172 protein content was lower than that found in teff $(12.84 \pm 0.51)$ and buckwheat $(12.39 \pm$

173 0.38) flours (Hager \& Arendt, 2013). However, it was higher than that found in the

174 most commonly used GF flours such as maize $(5.50 \%)$, rice $(7.33 \%)$, cassava $(1.4 \%)$ or 
sweet potato (6.3\%) flours (Hager et al., 2013; Pasqualone et al., 2010a, 2010b; Yadav,

176 Guha, Tharanathan \& Ramteke, 2006).

178 The suitability of Colocasia spp. cormels flour (F1) for GF breadmaking was evaluated

179 testing the different alternatives that the literature offers for building up inner structures.

180 Nevertheless, the amount of water used for making GF breads was based on the water

181 binding capacity of the flour $(2.27 \mathrm{~g} / \mathrm{g}$ flour $)$, since that parameter has been previously

182 confirmed as a good indicator of the optimum amount of water to be used in gluten free

183 systems (Espinosa-Ramírez, Garzon, Serna-Saldivar, \& Rosell, 2018). Resulting GF

184 breads were characterized regarding their moisture content, weight loss, specific volume

185 and crumb color (Table 2). The observed moisture content (44.29 - 50.64\%), specific

186 volume and weight lost in F1 breads were comparable to GF rice-based breads such as

187 oat, quinoa and so on (Hager et al., 2012). Likely, the higher water binding capacity of

188 Colocasia spp. flour (Calle et al., 2019) compared to other common GF flours and

189 starches (Martínez \& Gómez, 2017), might be responsible for those high values of

190 moisture content.

191 The color of bread is one of the first characteristics observed by consumers, determining

192 choice and preference. Results from the crumb color parameters are summarized in

193 Table 2. As expected, the color of F1 breads was visually dark, which was further

194 confirmed by their lower $L^{*}$ value. This value could be attributed to the natural color of

195 raw Colocasia spp. flour, which displayed 81.05 $\pm 0.36,1.17 \pm 0.07$ and $14.63 \pm 0.45$

196 for $L^{*}, a^{*}$ and $b^{*}$, respectively. Kumar, Sharma, Kaushal and Singh (2014) highlighted

197 that Colocasia spp. flour can contain naturally colored pigments and those affected the

198 color characteristics of end products. 
199 To describe the texture of the Colocasia spp. -based breads (F1), crumb hardness,

200 cohesiveness, chewiness, resilience and springiness are depicted in Table 3. Resulting

201 breads revealed much lower crumb texture values than those reported for commercial

202 GF bread (Matos \& Rosell, 2012), probably due to the higher moisture contents (de la

203 Hera, Rosell \& Gomez, 2014).

\subsection{Effect of additives in Colocasia spp. cormels flour-based breads}

205 Different strategies previously reported to build up inner structures in gluten free breads

206 or improve flour functionality were applied to increase the technological quality of

207 Colocasia spp. breads. The effect of thermally treated Colocasia spp flour blended with

208 the raw flour (F2), hydrocolloids (F3, F4), enzymes (F5-F7) or potato starch (F8) in the

209 quality of Colocasia spp. based breads were evaluated (Table 2). Those formulations

210 have been selected from literature to show the different alternatives applied to improve

211 GF breads quality. Among them, hydrocolloids of different nature -HPMC (Marco et

212 al., 2008), mixture of HPMC, xanthan gum and guar gum (Calle et al., 2014), enzymes

213 with strengthening (glucose oxidase) or weakening action (proteases), and potato starch.

214 The statistical analysis revealed significant differences $(\mathrm{p}<0.05)$ regarding moisture

215 content, weight loss and specific volume. In general, the effect of treated Colocasia spp.

216 flour (F2) as well as hydrocolloids (F3, F4) and enzymes addition (F5-F7) resulted in

217 higher moisture content than those observed in F1 breads. Overall, F2 and F7 samples

218 displayed the highest moisture content. F2 bread was obtained replacing Colocasia spp.

219 cormels flour by pretreated Colocasia spp. cormels flour. The pretreatment involved the

220 heating of the flour in excess of water to cause a partial or complete gelatinization of the

221 starch granules, which increase its ability to bind water (Njintang \& Mbofung, 2006).

222 On the other hand, F7 breads that incorporates a protease (Alcalase 1.5 MG Type FG) in

223 its recipe, might bind more water due to the hydrophobicity reduction of the flour. Some 
authors explained the effect of the protease on gluten free flours due to its hydrolytic action on the proteins, that led to a decrease in the hydrophobicity of the system in specific flours (Renzetti \& Arendt, 2009b). Nevertheless, no general trend could be defined regarding proteases, since that effect was not observed in F6 that also contained a protease type enzyme. Conversely, F8 breads displayed lower moisture content, likely due to the low capacity of potato starch to bind water (Benavent-Gil \& Rosell, 2017a).

230 In line with previous findings (Cornejo et al., 2015; Matos et al., 2013; Renzetti et al., 2009a; Shin, Gang \& Song, 2010), the specific volume values ranged from $1.11 \pm 0.05$ to $2.71 \pm 0.13 \mathrm{~mL} / \mathrm{g}$, values were significant dependent on the recipe applied. Compared to F1 breads, differences were only observed in the case of F6, F7 and F8 breads.

234 Among them, F6 breads displayed the highest specific volume, likely due to the enzyme 235 ability to modify protein functionality. Nevertheless, proteases effect on GF breads are really dependent on the type of flour (Renzetti \& Rosell, 2016). In fact, it seems that

237 iZyme improves breadmaking performance of cormels' flour. In opposition, the other 238 protease tested (alcalase) led to the smallest specific volume (F7). Small statistical 239 differences were also observed in the case of weight loss, particularly the lower weight 240 loss of F2 and F6 breads compared to F1 breads. However, in the case of F2 the water 241 ability retention of starch would be responsible of that effect, conversely in F6, it might 242 be ascribed to the more hydrophilic structure resulting from proteins hydrolysis.

243 The $L^{*}, a^{*}$ and $b^{*}$ values for crumb color showed significant $(\mathrm{p}<0.05)$ differences

244 among the different formulations used to obtain the GF breads. The lowest value of $L^{*}$

245 (lightness) was obtained for F8, which could be expected due to the opacity that confers 246 the potato starch. Regarding $a^{*}$ and $b^{*}$ values, all samples exhibited positive values,

247 indicating hue on red and yellow axis for all bread samples. However, significant 248 variation was observed among the different formulations. HPMC present in F3 was the 
unique additive that did not modify the $a^{*}$ value, compared to the control. The rest of recipes showed a decrease in the $a^{*}$ values. Regarding the $b^{*}$ parameter, again could be distinguished the effect of HPMC, leading to brownish crumb in F3; in contract, more pale crumbs were obtained when adding potato starch. Therefore, crumbs color was not only dependent on the flour color, but on the interaction of ingredients and additives.

254 As expected, crumb texture was significantly $(\mathrm{p}<0.05)$ influenced by the recipe applied 255 (Table 3). Hardness values ranged from $191 \pm 9$ to $361 \pm 17$ g. Overall, F2 and F7 breads displayed the highest and lowest values, respectively.

The hardness of F3 and F4 increased, despite the hydrocolloid addition usually tends to decrease hardness (Liu et al., 2018). Nonetheless, their effect seems to be also dependent on the flour used Sasaki (2018). Again, enzymes effect on crumb hardness was really erratic, particularly in the case of proteases that increase (F6) or decrease (F7) it, depending on the type of protease (Kawamura-Konishi, Shoda, Koga \& Honda, 2013). It should be emphasized that although general consensus exits about the inverse relationship between specific volume and crumb hardness, recipes tested in this study confirmed that additives/enzymes modify constituents network and in consequence the crumb structure, breaking down that general rule.

Noticeable differences were also showed in chewiness. In general, the ingredients addition increased this parameter, except in the case of F7 breads, which did not modify it. In the case of cohesiveness, all breads exhibited similar behavior, except in the case of F2, F5 and especially F8 bread that increased this parameter, suggesting a more

270 integrated matrix. Among them, F8 breads showed the highest value. Consumer's acceptance is greatly influenced by the cohesiveness, which quantifies the internal resistance of material. Therefore, starch addition led to more compact structure, since it

273 decreased the crumbling. Starch addition (F8) also affected significantly the resilience 
and springiness of the breads. Springiness has been commonly related with resilience

275

276

277

values, which reduction indicates the loss of crumb elasticity (Onyango, Mutungi, Unbehend \& Lindhauer, 2011). Considering the overall texture results, it seems that starch addition it is advisable to improve the texture properties of Colocasia spp. based breads.

\subsection{Digestibility of GF breads}

Relevant starch fractions including RDS, SDS and RS were evaluated and categorized depending on its rate of digestion (Table 4) (Englyst et al., 1996). Colocasia spp. cormels flour-based breads (F1) exhibited high SDS and RS fractions and low RDS fraction. Considering the great impact of RDS on the glycemic response (Englyst et al., 1996), the production of GF breads with higher amounts of SDS and RS fractions are interesting from a nutritional point of view. It has been already known the healthy profile of Colocasia spp. starch due to their small size (Temesgen \& Retta, 2015b), but what this study shows, is that the healthy profile is even present in the Colocasia spp. based breads.

In general, the starch fraction pattern observed in F1 breads was also found in the rest of the breads, except in the case of potato starch addition (F8). Nevertheless, the different recipes caused changes in $\alpha$-amylase susceptibility, resulting in significantly $(p<0.05)$ differences within RDS contents without significantly affecting the SDS and RS content (Table 4). The largest increase of RDS fraction was found in F8 samples, which is consistent with the pattern previously reported for starchy foods (Poutanen, Flander, \& Katina, 2009). Furthermore, studies conducted by Segura et al. (2011) highlighted that RDS is the most predominant fraction in available commercial GF breads mainly based on corn starch. This effect could be attributed to the starch gelatinization (Shumoy, Van 
298 Bockstaele, Devecioglu \& Raes, 2018), which results in a rapid degradation of starch

299 (Poutanen et al., 2009).

$300 \quad$ 3.5.In vitro and expected glycemic index of GF breads

301 The different gluten free breads were subjected to in vitro enzymatic hydrolysis in order

302 to simulate starch digestibility. At specific intervals of in vitro reaction, starch

303 hydrolysis was measured as glucose released and Figure 1 shows the resulting plots.

304 Furthermore, primary and secondary parameters derived from the in vitro digestion

305 were also analyzed. Results obtained including the kinetic constant $(k)$, equilibrium

306 concentration of hydrolyzed starch $\left(C_{\infty}\right)$, area under the hydrolysis curve after $180 \mathrm{~min}$

307 (Liu et al.), hydrolysis index (HI) and estimated glycemic index (eGI) are summarized

308 in Table 4. Starch hydrolysis draws plots characterized by a linear increase of glucose

309 released during the early stage of digestion, which can be maintained over time or reach

310 the plateau (Blazek \& Gilbert, 2010). In this regard, a typical digestion pattern was

311 observed for F1 breads, which at the early stage of hydrolysis exhibited a linear increase

312 in the amount of glucose released. Nevertheless, the kinetic constant $(k)$ for the

313 amylolysis evidenced slower hydrolysis kinetics than those observed by Segura et al.

314 (2011) when evaluated different commercial GF breads. After 90 min of in vitro

315 digestion, F1 breads reached the plateau, showing the maximum hydrolysis $\left(C_{\infty}\right)$ to a

316 lower extent than those previously reported (de la Hera et al., 2014). Following this

317 trend, lower $e G I$ was found compared with reported GF breads (de la Hera et al., 2014;

318 Liu et al., 2018; Segura et al., 2011; Wolter, Hager, Zannini \& Arendt, 2013). Some

319 authors reported that GF breads display significantly higher $e G I$ compared to traditional

320 breads (Segura et al., 2011). These results suggest that Colocasia spp. flour might

321 provide end products with higher nutritional properties. 
322 Concerning the influence of the different recipes, varying susceptibilities to enzyme

323 hydrolysis were observed (Figure 1). Starch hydrolysis exhibited different rate and

324 extent for Colocasia spp. based breads obtained from the diverse recipes (Table 4). The

325 kinetic constant $(k)$ of amylolysis ranged from $0.0249 \pm 0.0028$ to $0.0116 \pm 0.0053$,

326 displaying similar hydrolysis kinetics than F1 breads. Nevertheless, F8 samples

327 evidenced faster hydrolysis kinetics than those observed for the other samples, which

328 agrees with the increase of RDS above described. The maximum hydrolysis $\left(C_{\infty}\right)$ was

329 not significantly affected, thus all studied GF breads displayed similar extent of starch

330 hydrolysis than F1 breads. Nevertheless, ingredients addition had a significant effect ( $\mathrm{p}$

$331<0.05)$ on the HI, AUC and $e G I$ parameters, which showed similar trend. Results

332 obtained revealed that only the addition of potato starch increased the HI, AUC and $e G I$

333 parameters, while the addition of pretreated flour, gums or enzymes did not change

334 these parameters. Considering that in vitro glycemic index has been previously

335 correlated with RDS content (Liu et al., 2018), the greatest $e$ GI presented by F8 breads

336 could be explained by their large RDS content. In fact, a strong positive correlation was

337 observed between RDS content and $e G I(r=0.9498, \mathrm{p}<0.0100)$ in the present study.

338 Nevertheless, it is worth noting that the observed $e G I$ was lower than those previously

339 reported, even using potato starch in the formulation (de la Hera et al., 2014; Liu et al.,

340 2018; Segura et al., 2011; Wolter et al., 2013). These results suggest that Colocasia spp

341 flour could maintained its nutritional properties in complex food matrix.

342 4. Conclusions

343 The positive nutritional value of Colocasia spp. flour including high protein, minerals

344 and fiber content, as well as low fat content makes this ingredient attractive to enhance

345 the nutritional value of GF breads. However, to build up a light bread crumb structure

346 from Colocasia spp. flour requires the development of specific strategies. For doing so, 
347 different recipes have been tested in this study. By compiling results, it can be

348 concluded that proteases had a significant effect on the specific volume of breads, but

349 their effect was dependent on the type of proteases. Izyme increased the specific

350 volume, whereas alcalase type protease decreased it, but lead to softer crumbs. All GF

351 breads showed very appropriate pattern regarding starch digestibility, with high amount

352 of SDS and RS, which were not significantly affected with the recipes tested, and

353 neither the in vitro glycemic index. Within the tested recipes, the addition of potato

354 starch was the least advisable. Overall, Colocasia spp. flour can be used to produce GF

355 breads with similar technological quality parameters than those previously reported with

356 common GF flours, but with significantly better estimated glycemic index.

357 Acknowledgments of funding sources

358 Authors acknowledge the financial support of the Spanish Ministry of Science,

359 Innovation and Universities (AGL2014-52928-C2-1, RTI2018-095919-B-C21), and the

360 European Regional Development Fund and Generalitat Valenciana (Project Prometeo

$3612017 / 189)$.

362 References

363 AACC. (1999). Method 56-30.01 water hydration capacity of protein materials; method 44-15.02 moisture-Air-oven methods. AACC International (Ed.), Approved Methods of Analysis (11th ed.), AACC International, St. Paul, MN.

Alvarez-Jubete, L., Arendt, E., \& Gallagher, E. (2010). Nutritive value of pseudocereals and their increasing use as functional gluten-free ingredients. Trends in Food Science \& Technology, 21(2), 106-113.

Ammar, M., Hegazy, A., \& Bedeir, S. (2009). Using of taro flour as partial substitute of wheat flour in bread making. World Journal of Dairy \& Food Sciences, 4(2), 9499.

AOAC. (1990). Method 973.18. In (Vol. 1): AOAC Arlington, VA.

Arıcı, M., Yıldırım, R. M., Özülkü, G., Yaşar, B., \& Toker, O. S. (2016). Physicochemical and nutritional properties of taro ( Colocasia esculenta L. Schott) flour as affected by drying temperature and air velocity. Lwt, 74, 434440.

Benavent-Gil, Y., \& Rosell, C. M. (2017a). Morphological and physicochemical characterization of porous starches obtained from different botanical sources and amylolytic enzymes. Int J Biol Macromol, 103, 587-595. 
Benavent-Gil, Y., \& Rosell, C. M. (2017b). Performance of Granular Starch with Controlled Pore Size during Hydrolysis with Digestive Enzymes. Plant Foods Hum Nutr, 72(4), 353-359.

Blazek, J., \& Gilbert, E. P. (2010). Effect of enzymatic hydrolysis on native starch granule structure. Biomacromolecules, 11(12), 3275-3289.

Calle, J., Benavent-Gil, Y., Garzón, R., \& Rosell, C. M. (2019). Exploring the functionality of starches from corms and cormels of Xanthosoma sagittifolium. International Journal of Food Science \& Technology.

Calle, J., Villavicencio, M. N. d., Rosell, C. M., \& Bernabé-Marques, C. J. (2014). Influencia de mezclas de hidrocoloides en la reología de la masa del pan libre de gluten. Ciencia y Tecnología de Alimentos, Vol. 2, 37-42.

Capriles, V. D., \& Arêas, J. A. G. (2014). Novel approaches in gluten-free breadmaking: Interface between food science, nutrition, and health. Comprehensive Reviews in Food Science and Food Safety, 13(5), 871-890.

Capriles, V. D., dos Santos, F. G., \& Arêas, J. A. G. (2016). Gluten-free breadmaking: Improving nutritional and bioactive compounds. Journal of Cereal Science, 67, 83-91.

Chandrasekara, A., \& Josheph Kumar, T. (2016). Roots and Tuber Crops as Functional Foods: A Review on Phytochemical Constituents and Their Potential Health Benefits. Int J Food Sci, 2016, 3631647.

Cornejo, F., \& Rosell, C. M. (2015). Influence of germination time of brown rice in relation to flour and gluten free bread quality. J Food Sci Technol, 52(10), 65916598.

de la Hera, E., Rosell, C. M., \& Gomez, M. (2014). Effect of water content and flour particle size on gluten-free bread quality and digestibility. Food Chemistry, 151, 526-531.

do Nascimento, A. B., Fiates, G. M. R., dos Anjos, A., \& Teixeira, E. (2014). Glutenfree is not enough - perception and suggestions of celiac consumers. International Journal of Food Sciences and Nutrition, 65(4), 394-398.

Emmanuel, C. I., Osuchukwu, N., \& Oshiele, L. (2010). Functional and sensory properties of wheat (Aestium triticium) and taro flour (Colocasia esculenta) composite bread. African Journal of Food Science, 4(5), 248-253.

Englyst, H. N., Veenstra, J., \& Hudson, G. J. (1996). Measurement of rapidly available glucose (RAG) in plant foods: a potential in vitro predictor of the glycaemic response. British Journal of Nutrition, 75(3), 327-337.

Espinosa-Ramírez, J., Garzon, R., Serna-Saldivar, S. O., \& Rosell, C. M. (2018). Functional and nutritional replacement of gluten in gluten-free yeast-leavened breads by using $\beta$-conglycinin concentrate extracted from soybean flour. Food Hydrocolloids, 84, 353-360.

Gallagher, E., Gormley, T. R., \& Arendt, E. K. (2003). Crust and crumb characteristics of gluten free breads. Journal of Food Engineering, 56(2-3), 153-161.

Goñi, I., García-Alonso, A., \& Saura-Calixto, F. (1997). A starch hydrolysis procedure to estimate glycemic index. Nutrition Research, 17(3), 427-437.

Granfeldt, Y., Björck, I., Drews, A., \& Tovar, J. (1992). An in vitro procedure based on chewing to predict metabolic response to starch in cereal and legume products. The American Journal of Clinical Nutrition, 59(3), 777S-777S.

Gujral, H. S., \& Rosell, C. M. (2004). Improvement of the breadmaking quality of rice flour by glucose oxidase. Food Research International, 37(1), 75-81.

Hager, A.-S., \& Arendt, E. K. (2013). Influence of hydroxypropylmethylcellulose (HPMC), xanthan gum and their combination on loaf specific volume, crumb 
hardness and crumb grain characteristics of gluten-free breads based on rice, maize, teff and buckwheat. Food Hydrocolloids, 32(1), 195-203.

Hager, A.-S., Wolter, A., Czerny, M., Bez, J., Zannini, E., Arendt, E. K., \& Czerny, M. (2012). Investigation of product quality, sensory profile and ultrastructure of breads made from a range of commercial gluten-free flours compared to their wheat counterparts. European Food Research and Technology, 235(2), 333-344.

Kaushal, P., Kumar, V., \& Sharma, H. K. (2015). Utilization of taro (Colocasia esculenta): a review. Journal of Food Science and Technology, 52(1), 27-40.

Kawamura-Konishi, Y., Shoda, K., Koga, H., \& Honda, Y. (2013). Improvement in gluten-free rice bread quality by protease treatment. Journal of Cereal Science, 58(1), 45-50.

Kumar, V., Sharma, H. K., Kaushal, P., \& Singh, K. (2014). Optimization of taro-wheat composite flour cake using Taguchi technique. Journal of Food Measurement and Characterization, 9(1), 35-51.

Liu, X., Mu, T., Sun, H., Zhang, M., Chen, J., \& Fauconnier, M. L. (2018). Influence of different hydrocolloids on dough thermo-mechanical properties and in vitro starch digestibility of gluten-free steamed bread based on potato flour. Food chemistry, 239, 1064-1074.

Marco, C., \& Rosell, C. M. (2008). Breadmaking performance of protein enriched, gluten-free breads. European Food Research and Technology, 227(4), 12051213.

Martínez, M. M., \& Gómez, M. (2017). Rheological and microstructural evolution of the most common gluten-free flours and starches during bread fermentation and baking. Journal of food engineering, 197, 78-86.

Masure, H. G., Fierens, E., \& Delcour, J. A. (2016). Current and forward looking experimental approaches in gluten-free bread making research. Journal of Cereal Science, 67, 92-111.

Matos, M. E., \& Rosell, C. M. (2012). Relationship between instrumental parameters and sensory characteristics in gluten-free breads. European Food Research and Technology, 235(1), 107-117.

Matos, M. E., \& Rosell, C. M. (2013). Quality Indicators of Rice-Based Gluten-Free Bread-Like Products: Relationships Between Dough Rheology and Quality Characteristics. Food and Bioprocess Technology, 6(9), 2331-2341.

Morreale, F., Garzón, R., \& Rosell, C. M. (2018). Understanding the role of hydrocolloids viscosity and hydration in developing gluten-free bread. A study with hydroxypropylmethylcellulose. Food Hydrocolloids, 77, 629-635.

Njintang, Y. N., \& Mbofung, C. M. F. (2006). Effect of precooking time and drying temperature on the physico-chemical characteristics and in-vitro carbohydrate digestibility of taro flour. LWT - Food Science and Technology, 39(6), 684-691.

Onyango, C., Mutungi, C., Unbehend, G., \& Lindhauer, M. G. (2011). Modification of gluten-free sorghum batter and bread using maize, potato, cassava or rice starch. LWT - Food Science and Technology, 44(3), 681-686.

Pasqualone, A., Caponio, F., Summo, C., Paradiso, V. M., Bottega, G., \& Pagani, M. A. (2010a). Gluten-free bread making trials from cassava (Manihot esculenta Crantz) flour and sensory evaluation of the final product. International Journal of Food Properties, 13(3), 562-573.

Pasqualone, A., Caponio, F., Summo, C., Paradiso, V. M., Bottega, G., \& Pagani, M. A. (2010b). Gluten-Free Bread Making Trials from Cassava (Manihot EsculentaCrantz) Flour and Sensory Evaluation of the Final Product. International Journal of Food Properties, 13(3), 562-573. 
Pellegrini, N., \& Agostoni, C. (2015). Nutritional aspects of gluten-free products. Journal of the Science of Food and Agriculture, 95(12), 2380-2385.

Poutanen, K., Flander, L., \& Katina, K. (2009). Sourdough and cereal fermentation in a nutritional perspective. Food microbiology, 26(7), 693-699.

Renzetti, S., \& Arendt, E. K. (2009a). Effect of protease treatment on the baking quality of brown rice bread: From textural and rheological properties to biochemistry and microstructure. Journal of Cereal Science, 50(1), 22-28.

Renzetti, S., \& Arendt, E. K. (2009b). Effects of oxidase and protease treatments on the breadmaking functionality of a range of gluten-free flours. European Food Research and Technology, 229(2), 307-317.

Renzetti, S., \& Rosell, C. M. (2016). Role of enzymes in improving the functionality of proteins in non-wheat dough systems. Journal of Cereal Science, 67, 35-45.

Sanful, R. E. (2011). Organoleptic and nutritional analysis of taro and wheat flour composite bread. World Journal of Dairy and Food Sciences, 6(2), 175-179.

Sasaki, T. (2018). Effects of xanthan and guar gums on starch digestibility and texture of rice flour blend bread. Cereal Chemistry, 95(1), 177-184.

Segura, M. E., \& Rosell, C. M. (2011). Chemical composition and starch digestibility of different gluten-free breads. Plant Foods Hum Nutr, 66(3), 224-230.

Shin, M., Gang, D.-O., \& Song, J.-Y. (2010). Effects of protein and transglutaminase on the preparation of gluten-free rice bread. Food Science and Biotechnology, 19(4), 951-956.

Shumoy, H., Van Bockstaele, F., Devecioglu, D., \& Raes, K. (2018). Effect of sourdough addition and storage time on in vitro starch digestibility and estimated glycemic index of tef bread. Food Chem, 264, 34-40.

Temesgen, M., \& Retta, N. (2015a). Nutritional potential, health and food security benefits of taro Colocasia esculenta (L.): A review. Food Science and Quality Management, 36, 23-30.

Temesgen, M., \& Retta, N. (2015b). Nutritional Potential, Health and Food Security Benefits of Taro Colocasia Esculenta (L.): A Review. Food Science and Quality Management, 36, 23-31.

Wolter, A., Hager, A.-S., Zannini, E., \& Arendt, E. K. (2013). In vitro starch digestibility and predicted glycaemic indexes of buckwheat, oat, quinoa, sorghum, teff and commercial gluten-free bread. Journal of Cereal Science, 58(3), 431-436.

Yadav, A. R., Guha, M., Tharanathan, R., \& Ramteke, R. (2006). Changes in characteristics of sweet potato flour prepared by different drying techniques. LWT-Food Science and Technology, 39(1), 20-26. 


\section{FIGURE CAPTIONS}

520 Figure 1. Starch hydrolyzed during in vitro starch digestibility of gluten-free breads

521 based on Colocasia spp. cormels flour, pretreated or blended with different additives.

522

523 
Table 1. Gluten free bread recipes

\begin{tabular}{lcccccccc}
\hline Ingredients & F1 & F2 & F3 & F4 & F5 & F6 & F7 & F8 \\
\hline Flour (g) & 100 & 100 & 100 & 100 & 100 & 100 & 100 & 80 \\
Water (g) & 227 & 227 & 227 & 227 & 227 & 227 & 227 & 227 \\
Salt (g) & 1.5 & 1.5 & 1.5 & 1.5 & 1.5 & 1.5 & 1.5 & 1.5 \\
Compressed Yeast (g) & 3 & 3 & 3 & 3 & 3 & 3 & 3 & 3 \\
Sugar (g) & 2 & 2 & 2 & 2 & 2 & 2 & 2 & 2 \\
Oil (g) & 2 & 2 & 2 & 2 & 2 & 2 & 2 & 2 \\
HPMC (g) & & & 2 & 0.29 & & & & \\
Xanthan gum (g) & & & & 0.21 & & & &
\end{tabular}

Gluzyme Mono 10000 BG (g) 0.01

iZyme BA (g)

0.1

Alcalase 1.5 MG Type FG (g)

Potato starch (g)

526 Ingredients: $100 \%$ of rhizome flour (F1); $50 \%$ of Colocasia spp. cormels flour blended with 50\% of pre-treated Colocasia spp. cormels flour 527 (F2); 100\% of flour blended with hydrocolloids (F3 and F4); 100\% of flour blended with enzymes (F5, F6 and F7); and 80\% of flour blended 528 with $20 \%$ of potato starch (F8). 

ingredients, additives or processing aids.

\begin{tabular}{lcccccc}
\hline & $\begin{array}{c}\text { Moisture } \\
(\mathrm{g} / 100 \mathrm{~g})\end{array}$ & $\begin{array}{c}\text { Weight loss } \\
(\%)\end{array}$ & $\begin{array}{c}\text { Specific volume } \\
(\mathrm{mL} / \mathrm{g})\end{array}$ & $L^{*}$ & $a^{*}$ & $b^{*}$ \\
\hline F1 & $57.63 \pm 0.26 \mathrm{~b}$ & $15.49 \pm 0.69 \mathrm{bc}$ & $1.74 \pm 0.03 \mathrm{~b}$ & $57.01 \pm 0.37 \mathrm{c}$ & $6.88 \pm 0.38 \mathrm{e}$ & $22.29 \pm 0.63 \mathrm{c}$ \\
F2 & $60.23 \pm 0.18 \mathrm{ef}$ & $12.78 \pm 0.60 \mathrm{a}$ & $1.63 \pm 0.02 \mathrm{~b}$ & $57.48 \pm 0.49 \mathrm{c}$ & $5.18 \pm 0.10 \mathrm{~b}$ & $20.34 \pm 0.25 \mathrm{~b}$ \\
F3 & $58.74 \pm 0.61 \mathrm{c}$ & $14.93 \pm 0.97 \mathrm{bc}$ & $1.70 \pm 0.05 \mathrm{~b}$ & $56.87 \pm 0.66 \mathrm{bc}$ & $7.09 \pm 0.82 \mathrm{e}$ & $23.97 \pm 0.66 \mathrm{~d}$ \\
F4 & $58.80 \pm 0.41 \mathrm{~cd}$ & $13.80 \pm 0.81 \mathrm{ab}$ & $1.67 \pm 0.02 \mathrm{~b}$ & $56.09 \pm 0.49 \mathrm{bc}$ & $6.13 \pm 0.13 \mathrm{~d}$ & $21.04 \pm 0.53 \mathrm{~b}$ \\
F5 & $59.69 \pm 0.29 \mathrm{de}$ & $13.98 \pm 1.57 \mathrm{ab}$ & $1.65 \pm 0.09 \mathrm{~b}$ & $55.02 \pm 1.98 \mathrm{ab}$ & $5.85 \pm 0.30 \mathrm{~cd}$ & $21.75 \pm 0.96 \mathrm{~b}$ \\
F6 & $59.30 \pm 0.68 \mathrm{~cd}$ & $13.07 \pm 1.78 \mathrm{a}$ & $2.71 \pm 0.13 \mathrm{c}$ & $57.21 \pm 0.80 \mathrm{c}$ & $5.92 \pm 0.49 \mathrm{~cd}$ & $20.70 \pm 0.52 \mathrm{~b}$ \\
F7 & $60.96 \pm 0.17 \mathrm{f}$ & $13.89 \pm 1.03 \mathrm{ab}$ & $1.11 \pm 0.05 \mathrm{a}$ & $57.41 \pm 2.27 \mathrm{c}$ & $5.63 \pm 0.16 \mathrm{bc}$ & $20.74 \pm 0.40 \mathrm{~b}$ \\
F8 & $55.56 \pm 0.20 \mathrm{a}$ & $16.30 \pm 1.53 \mathrm{c}$ & $1.20 \pm 0.06 \mathrm{a}$ & $57.21 \pm 0.80 \mathrm{a}$ & $5.92 \pm 0.49 \mathrm{a}$ & $20.70 \pm 0.52 \mathrm{a}$ \\
\hline p-value & 0.0000 & 0.0031 & 0.0000 & 0.0029 & 0.0000 & 0.0000 \\
\hline
\end{tabular}

Values followed by different letters within a column denote significant differences. Ingredients: $100 \%$ of rhizome flour (F1); $50 \%$ of Colocasia 

ingredients, additives or processing aids.

\begin{tabular}{lccccc}
\hline & Hardness $(\mathrm{g})$ & Cohesiveness & Chewiness $(\mathrm{g})$ & Resilience & Springiness \\
\hline F1 & $263 \pm 38 \mathrm{c}$ & $0.337 \pm 0.044 \mathrm{a}$ & $24 \pm 3 \mathrm{a}$ & $0.104 \pm 0.019 \mathrm{c}$ & $0.419 \pm 0.075 \mathrm{a}$ \\
F2 & $361 \pm 17 \mathrm{e}$ & $0.384 \pm 0.041 \mathrm{~b}$ & $69 \pm 17 \mathrm{e}$ & $0.126 \pm 0.013 \mathrm{~d}$ & $0.484 \pm 0.107 \mathrm{ab}$ \\
F3 & $316 \pm 12 \mathrm{~d}$ & $0.348 \pm 0.028 \mathrm{ab}$ & $50 \pm 4 \mathrm{~cd}$ & $0.095 \pm 0.010 \mathrm{a}-\mathrm{c}$ & $0.441 \pm 0.087 \mathrm{ab}$ \\
F4 & $323 \pm 23 \mathrm{~d}$ & $0.313 \pm 0.044 \mathrm{a}$ & $45 \pm 6 \mathrm{~cd}$ & $0.091 \pm 0.009 \mathrm{ab}$ & $0.434 \pm 0.135 \mathrm{a}$ \\
F5 & $209 \pm 16 \mathrm{ab}$ & $0.373 \pm 0.020 \mathrm{~b}$ & $39 \pm 14 \mathrm{bc}$ & $0.103 \pm 0.009 \mathrm{c}$ & $0.546 \pm 0.193 \mathrm{~b}$ \\
F6 & $330 \pm 18 \mathrm{~d}$ & $0.331 \pm 0.037 \mathrm{a}$ & $54 \pm 3 \mathrm{de}$ & $0.101 \pm 0.012 \mathrm{bc}$ & $0.473 \pm 0.116 \mathrm{ab}$ \\
F7 & $191 \pm 9 \mathrm{a}$ & $0.334 \pm 0.030 \mathrm{a}$ & $27 \pm 4 \mathrm{ab}$ & $0.086 \pm 0.008 \mathrm{a}$ & $0.473 \pm 0.111 \mathrm{ab}$ \\
F8 & $233 \pm 17 \mathrm{~b}$ & $0.500 \pm 0.031 \mathrm{c}$ & $65 \pm 6 \mathrm{e}$ & $0.143 \pm 0.019 \mathrm{e}$ & $0.697 \pm 0.090 \mathrm{c}$ \\
\hline p-value & 0.0000 & 0.0000 & 0.0000 & 0.0000 & 0.0001 \\
\hline
\end{tabular}

539 Values followed by different letters within a column denote significant differences.

540 Ingredients: $100 \%$ of rhizome flour (F1); $50 \%$ of Colocasia spp. cormels flour blended with 50\% of pre-treated Colocasia spp. cormels flour 541 (F2); 100\% of flour blended with hydrocolloids (F3 and F4); 100\% of flour blended with enzymes (F5, F6 and F7); and 80\% of flour blended 542 with $20 \%$ of potato starch (F8). 
blended with different ingredients, additives or processing aids.

\begin{tabular}{|c|c|c|c|c|c|c|c|c|}
\hline & $\begin{array}{c}\text { RDS } \\
(\mathrm{mg} / 100 \mathrm{mg})\end{array}$ & $\begin{array}{c}\text { SDS } \\
(\mathrm{mg} / 100 \mathrm{mg})\end{array}$ & $\begin{array}{c}\mathrm{RS} \\
(\mathrm{mg} / 100 \mathrm{mg})\end{array}$ & $K$ & $C_{\infty}$ & AUC & $\mathrm{HI}$ & $e G I$ \\
\hline $\mathrm{F} 1$ & $4.98 \pm 0.51 \mathrm{ab}$ & $7.316 \pm 0.035$ & $6.032 \pm 0.344$ & $0.0127 \pm 0.0020 a b$ & $15.82 \pm 0.48$ & $1715 \pm 81 a b$ & $19.01 \pm 0.89 \mathrm{ab}$ & $24.58 \pm 0.77 \mathrm{ab}$ \\
\hline $\mathrm{F} 2$ & $5.32 \pm 0.48 \mathrm{a}-\mathrm{c}$ & $6.232 \pm 1.391$ & $5.959 \pm 0.370$ & $0.0173 \pm 0.0028 a b$ & $13.32 \pm 2.77$ & $1643 \pm 245 a b$ & $18.21 \pm 2.71 \mathrm{ab}$ & $23.90 \pm 2.34 \mathrm{ab}$ \\
\hline $\mathrm{F} 3$ & $4.38 \pm 0.40 \mathrm{a}$ & $6.895 \pm 1.309$ & $6.730 \pm 0.393$ & $0.0116 \pm 0.0053 \mathrm{a}$ & $16.10 \pm 4.90$ & $1565 \pm 92 \mathrm{a}$ & $17.35 \pm 1.02 \mathrm{a}$ & $23.15 \pm 0.88 \mathrm{a}$ \\
\hline $\mathrm{F} 4$ & $7.01 \pm 0.40 \mathrm{bc}$ & $5.809 \pm 0.094$ & $6.492 \pm 0.362$ & $0.0243 \pm 0.0016 a b$ & $13.56 \pm 0.17$ & $1885 \pm 57 \mathrm{ab}$ & $20.89 \pm 0.64 \mathrm{ab}$ & $26.20 \pm 0.55 \mathrm{ab}$ \\
\hline F5 & $6.05 \pm 2.17 \mathrm{a}-\mathrm{c}$ & $7.298 \pm 0.692$ & $7.228 \pm 1.085$ & $0.0161 \pm 0.0091 \mathrm{ab}$ & $16.66 \pm 1.75$ & $1897 \pm 286 b$ & $21.02 \pm 3.17 \mathrm{~b}$ & $26.32 \pm 2.74 \mathrm{~b}$ \\
\hline F6 & $5.25 \pm 0.49 \mathrm{a}-\mathrm{c}$ & $5.632 \pm 0.652$ & $7.178 \pm 1.184$ & $0.0189 \pm 0.0043 a b$ & $12.25 \pm 0.92$ & $1560 \pm 7 \mathrm{a}$ & $17.29 \pm 0.08 \mathrm{a}$ & $23.10 \pm 0.07 \mathrm{a}$ \\
\hline F7 & $7.29 \pm 0.56 \mathrm{c}$ & $5.864 \pm 0.313$ & $5.153 \pm 0.387$ & $0.0249 \pm 0.0028 b$ & $13.87 \pm 0.01$ & $1939 \pm 59 b$ & $21.49 \pm 0.66 b$ & $26.72 \pm 0.57 b$ \\
\hline F8 & $12.36 \pm 0.84 \mathrm{~d}$ & $3.815 \pm 1.174$ & $7.207 \pm 0.329$ & $0.0486 \pm 0.0100 \mathrm{c}$ & $16.24 \pm 0.40$ & $2576 \pm 7 \mathrm{c}$ & $28.55 \pm 0.08 \mathrm{c}$ & $32.81 \pm 0.07 \mathrm{c}$ \\
\hline$p$-value & 0.0005 & 0.0514 & 0.1006 & 0.0031 & 0.3868 & 0.0017 & 0.0017 & 0.0017 \\
\hline
\end{tabular}

547 Ingredients: $100 \%$ of rhizome flour (F1); $50 \%$ of Colocasia spp. cormels flour blended with 50\% of pre-treated Colocasia spp. cormels flour 548 (F2); 100\% of flour blended with hydrocolloids (F3 and F4); 100\% of flour blended with enzymes (F5, F6 and F7); and 80\% of flour blended 549 with $20 \%$ of potato starch (F8).

550 Values followed by different letters within a column denote significant differences

$551 C_{\infty}$ and $k$ were quantified following the equation, $C=C_{\infty}\left(1-\mathrm{e}^{-k t}\right)$

$552 e G I$ was estimated as reported Goñi et al. (1997) 
553 Figure 1.

554

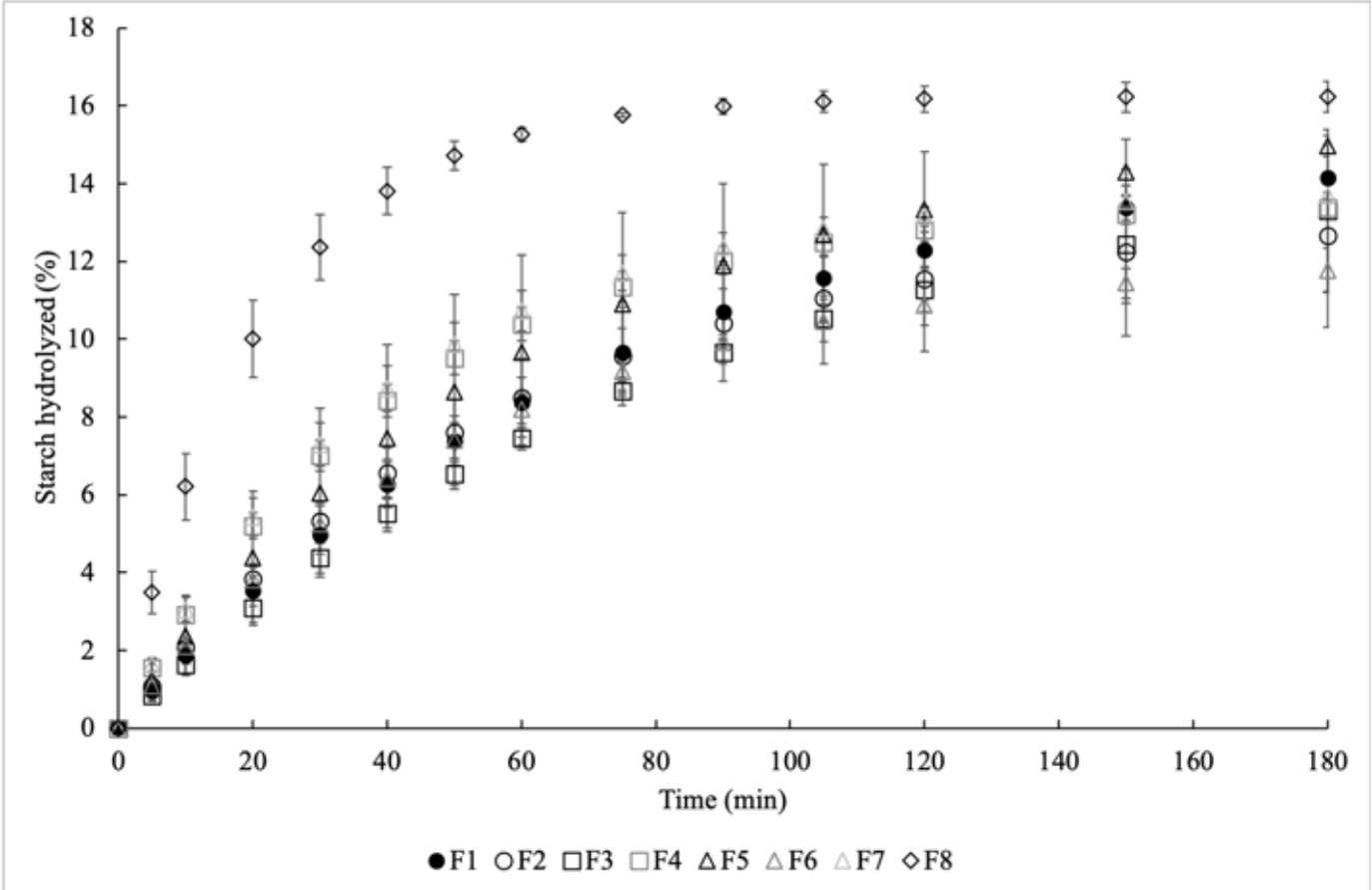


